\section{Para além do Estado: Marx, Lenin e a crítica da estatalidade}

Recebido: 26.07 .19 Aprovado: 17.04.20

\begin{abstract}
Rafael Afonso da Silva*
Resumo: A leitura da crítica marxiana da estatalidade tem sido conduzida, em parte da literatura especializada, sob o pressuposto de uma dupla identidade: da própria obra marxiana e da tradição do pensamento marxista. Contrapondo-se a essa grade de leitura e identificando em Lenin o seu iniciador, o artigo explora as diferenças entre as críticas marxiana e leniniana da estatalidade, argumentando que essas diferenças derivam fundamentalmente do modo como se articulam a crítica do Estado e a problematização das formas econômicas de cooperação do capital. Na conclusão, destaca-se a importância da abordagem marxiana, que, no contexto defensivo da resistência à "pilhagem" do público-estatal, nos convida a analisar os regimes de práticas que estruturam as formas privada e pública de produção ou regulação de "bens" e "serviços" e a produzir tecnologias de "autotrabalho" e "autogoverno" na multiplicação de formas associativas orientadas para a "reabsorção" dos poderes subsumidos pelos dispositivos econômicos e políticos do capital.
\end{abstract}

Palavras-chave: Estado. Poder político. Revolução social. Lenin. Marx.

\section{Beyond the state: Marx, Lenin, and the critique of statehood}

Abstract: The reading of the Marxian critique of statehood has been conducted in much of the specialized literature under the assumption of the identity: of the Marxian work itself and of the Marxist thinking. Opposing this reading tradition, the article explores the differences between the Marxian and Leninian critiques of statehood, arguing that these differences derive fundamentally from the way in which state criticism and the problematization of economic forms of capital cooperation are articulated with each other. In conclusion, it is highlighted the importance of the Marxian approach, which, in the context of the resistance to the "pillage" of the state-public, invites to analyze the regimes of practices that structure the private and public forms of production or regulation of "goods" and "services", as well as to produce "self-working" and "self-governing" technologies in the multiplication of associative forms founded on the "reabsorption" of the powers subsumed by the economic and political mechanisms of capital.

Keywords: State. Political power. Social revolution. Lenin. Marx.

\author{
* Rafael Afonso \\ da Silva é doutor \\ em sociologia pelo \\ Instituto de Filosofia \\ e Ciências Humanas \\ da Universidade \\ Estadual de \\ Campinas (Unicamp), \\ Campinas, São Paulo, \\ Brasil. \\ Orcid: 0000-0003- \\ 4701-3565. \\ <raafonso@unicamp. \\ br $>$.
}


1. Pogrebinschi

(2009) defende

o conceito de

"definhamento

do Estado" como

transversal a toda

a análise marxiana

do político. Mas sua

interpretação desse

conceito rompe

radicalmente com

a problemática

leniniana do

"definhamento

do Estado". Não é

possível desenvolver

aqui a análise

da autora. Vale

registrar, contudo,

que a palavra de

"definhamento"

não reaparece nos

escritos marxianos

de 1871. Além disso,

o termo tem uma

carga semântica

que não advoga

pelo seu uso. Ele

se aproxima muito

de uma analogia

com a biologia, que,

aliás, não é estranha

às abordagens

engelsiana e

leniniana. Sitton

(1989: 2) já

sublinhava que o uso

do verbo absterben

(definhar) por

Engels compreende

"uma metáfora

tomada da natureza,

implicando um

processo automático

e determinado".

A ênfase de Lenin

(1986: 87) na

analogia entre a

abordagem marxiana

do comunismo

e a abordagem

naturalista do

"desenvolvimento

de uma nova espécie

biológica" apenas

reforça esse sentido.

Essa analogia

"introduz, em uma

implicação recíproca

(meta-histórica e

\section{Introdução}

enin (1986) apresenta Estado e revolução como expressão da "doutrina do marxismo sobre o Estado". Desse modo, localiza sua abordagem em uma linha de continuidade com a produção de Marx e Engels. A pressuposição dessa identidade, de algo que se denomina "doutrina do marxismo sobre o Estado", e a projeção de Lenin como fiel comentador desse "grande texto", extensível apenas pela reposição daquela identidade, continuam a produzir efeitos. Refiro-me, em primeiro lugar, à reafirmação do status de Lenin como "codificador" e "atualizador" das "descobertas, conclusões e ensinamentos práticos de Marx, Engels e outros pensadores marxistas" sobre a questão do Estado (Fernandes, 2010: 12). Mas, além disso, vale considerar também a presença persistente, na análise do pensamento marxiano, de certas categorias, seja daquelas extraídas diretamente da obra de Lenin, como "semiEstado" e "definhamento do Estado", ou de outras que orbitam a problemática leniniana, como "novo Estado", "Estado de transição" e "Estado socialista".

Ao recusar essa abordagem, sustento, na análise dos escritos de Marx (1978) sobre a Comuna de Paris, argumentação mais próxima de autores como Sayer e Corrigan (1987), Sitton (1989), Pogrebinschi (2009)1 e Tible (2014). Ao se opor explicitamente a esse jogo de identidades ou repondo a perspectiva de Marx na década de 1870 como associada à fórmula estratégica da "forma-comuna contra o Estado" (Tible, 2014: 80), esses autores permitem perceber a impropriedade desse jogo. Em face desse conjunto de autores, a novidade da discussão empreendida neste artigo decorre, sobretudo, da relação estabelecida com a plataforma conceitual da "subsunção real" do trabalho ao capital e das consequências dessa leitura para a compreensão de alguns temas fulcrais na concepção marxiana da "forma-comuna contra o Estado", como a "centralização" e a "regulação social" da produção².

O artigo está dividido em quatro partes. A primeira analisa a crítica leniniana da estatalidade e seus limites. A segunda explora a abordagem de Marx do tema do Estado e da revolução social nos escritos sobre a Comuna de Paris, designadamente, Guerra civil na França e seus esboços, diferenciando-a da abordagem leniniana. A terceira aprofunda a análise dessa diferença, situando a discussão da centralização em ambas as abordagens. A quarta procura compreender, para mais da vagueza das proposições de Marx nos escritos em questão, como se poderia conciliar sua crítica à centralização política com a perspectiva da regulação da produção social por um "plano comum". 


\section{"Todo o poder aos sovietes" e os limites da crítica leniniana da estatalidade}

A interpretação que segue rejeita as leituras que atribuem a Lenin uma concepção meramente instrumentalista do Estado (Althusser, 1980; Bobbio, 1980; Poulantzas, 2000). Diversamente, argumenta-se que Lenin, na crítica da estatalidade, em seus escritos de 1917, introduz um quadro analítico em que a problematização da forma institucional assume lugar central, de modo que seus limites devem ser buscados no interior dessa mesma problematização.

Muitos comentadores concordam que os escritos leninianos de 1917 conduzem a nova abordagem do tema do Estado e da revolução. Como testemunham suas anotações de janeiro e fevereiro de 1917 (Lenin, 1986), Lenin engajou-se nessa reflexão antes do início da Revolução Russa, aparentemente como parte de um projeto intelectual e político mais amplo de confrontação com o marxismo hegemônico na época. Aparentemente, essa reflexão estava associada à sua análise do imperialismo e do capitalismo monopolista de Estado e à identificação do extraordinário desenvolvimento da burocracia "em toda parte", desde as estruturas parlamentares às estruturas organizativas dos partidos "socialistas". Nesse contexto, Lenin começa a identificar a estratégia de aperfeiçoamento da maquinaria estatal-burocrática com o "reformismo" e o "social-patriotismo". Com a deflagração da Revolução Russa e a reemergência do movimento sovietista em seu bojo, a elaboração de uma alternativa a essa estratégia é percebida por Lenin como tarefa urgente, de modo que ele se empenha em desenvolvê-la em cartas, falas e panfletos, antes de fazê-lo, de maneira mais detalhada, em Estado e revolução.

Talvez nenhuma outra fórmula política seja mais expressiva da originalidade da intervenção leniniana na Revolução Russa do que o slogan "todo o poder/soberania (vlast) aos sovietes". O slogan exprimia uma solução radical ao que era chamado na época de krisis vlasti, crise de poder/soberania, e traduzido normalmente na fórmula de um dvoevlastie, poder/soberania dual (Anweiler, 1974; Lih, 2017).

Segundo a compreensão corriqueira, o dvoevlastie remete à coexistência da autoridade do governo provisório e da autoridade das instituições do sovietismo. Mas a compreensão de Lenin não era a corriqueira. Partindo da problemática comum do vlast, ele introduziu uma perspectiva nova, ao assumir como fio condutor da análise a relação interna entre: a localização social do poder, traduzida na oposição entre vlast da minoria (exploradora) e da maioria (explorada) e entre suas respectivas figurações institucionais (governo provisório e sovietes); sua finalidade social, compreendida nos termos da oposição entre conservação e revolução ou ainda entre teleológica) entre origem e direção, a norma natural de uma entelékheia", vinculada ao esquema da "produção histórica do comum pelo capital" (Silva, 2017: 102).

2. Uma das implicações dessa abordagem é que a leitura de uma retomada por Marx em 1871 de uma perspectiva próxima àquela de seus escritos de 1843-1844, como sustentado por Sayer \& Corrigan (1987), Sitton (1989) e Pogrebinschi (2009), pode ser problemática, ainda que amparada em analogias muito evidentes entre alguns trechos de 1843-1844 e 1871. Sayer \& Corrigan (1987: 74), no entanto, não deixam de reconhecer, como "novidade" dos escritos da década de 1870, o aprofundamento do significado da "divisão do trabalho", o que apenas corrobora a leitura defendida aqui. Como esse ângulo da discussão não interessa diretamente ao argumento desenvolvido no artigo, não será objeto de considerações mais detalhadas. 
revolução da minoria (interrompida na "fase" burguesa da revolução) e revolução da maioria (desdobrada em revolução proletário-camponesa); e forma política, ou seja, a oposição entre lógica estatal e lógica sovietal ou comunal do poder. Desse modo, não é legítimo afirmar que "o que importa", para Lenin, é apenas "a relação real de domínio entre classe dominante e classe dominada" que se exerce por meio do Estado (Bobbio, 1980: 155), na medida em que essa relação não pode ser compreendida sem a investigação da forma institucional do poder.

Para Lenin, a estatalidade baseia-se na distinção entre a coletividade (minoria) que participa da produção normativa ou do poder de decisão, sendo capaz, em última instância, de suspender a validade do ordenamento normativo, e a coletividade (maioria) atada à vigência cogente desse ordenamento. Essa distinção ancora-se na existência de uma rede de instituições autonomizadas e capazes de internalizar os processos de tomada de decisão e exteriorizar a vigência das decisões. O dispositivo como um todo pode ser compreendido como um processo de "externalização e duplicação do poder da classe dominante" (Demier \& Gonçalves, 2017: 2361), na forma da "autonomização dos meios organizados do poder de Estado (coercivos, administrativos e decisórios) em relação à 'sociedade'”" (Silva, 2017: 99).

A estatalidade é, por isso, um modo de instituição do vlast incompatível com a inversão da relação entre maioria e minoria de que depende a revolução proletário-camponesa. Esta precisa instituir uma nova forma política, em que a maioria (e progressivamente o conjunto da sociedade) participe da produção das regras que a afetem e seja capaz de suspender e alterar o ordenamento normativo, fazendo com que seu caráter impositivo decorra da coparticipação nos processos de tomada de decisão.

Em sua análise do dvoevlastie, em texto que carrega esse tema no título, após enunciar a necessidade de um novo "tipo de poder", Lenin estipula, como seu primeiro traço ou condição, que

a fonte do poder não está em uma lei, previamente discutida e aprovada pelo Parlamento, mas na iniciativa direta das massas desde baixo e em todo lugar, na conquista "direta" do poder, para empregar termo em voga (Lenin, 1985: 154).

Isso significa que à atividade instituinte das massas não se pode sobrepor nenhuma instituição ou normatividade legalmente articulada. Os outros traços desse novo "tipo de poder" (como a substituição da polícia e do exército pelo "armamento direto de todo o povo" e a execução direta das decisões pelas massas ou a elegibilidade, revogabilidade e rotatividade de todos os funcionários necessários para a 
execução de funções/decisões específicas) ${ }^{3}$ decorrem do mesmo princípio e orientam-se para evitar "recapturas" do poder por instituições específicas e por minorias nelas alojadas.

Com a proposição de que "a fonte do poder não está em uma lei" e com a sua localização na "iniciativa direta", Lenin sugere uma dinamicidade entre instituído e instituinte não limitada pelo primeiro. Pelo contrário, a norma instituída é o que deve ser a todo momento excedido pelo movimento instituinte das massas, pelas necessidades da transformação social. O direito é, assim, incluído na vida, na transformação, ao invés de ser postulado como sua estabilização. A nova configuração do vlast, que, em oposição à estatal e pensando nas referências históricas que Lenin tem em mente, poderíamos chamar de comunal ou sovietal, descreveria a existência, fora do ordenamento jurídico, da atividade instituinte do movimento de massas.

Pode-se dizer que essas formulações leninianas se encontram engajadas em uma tentativa de esboçar um "projeto de autonomia social", no sentido de Castoriadis (2004). Para este, um "projeto de autonomia social" é aquele que visa engajar a coletividade na produção consciente e contínua de suas próprias normas, sem a pressuposição de nenhuma ordem prévia como padrão imutável ou limite dessa atividade. Reconhecer o esforço tentativo de Lenin é mais interessante do que simplesmente identificar em Lenin "o verdadeiro criador do totalitarismo" (Castoriadis, 2002: 49), pois permite apreender, em um desdobramento da análise, como essa tentativa se desfigura, não somente por condições externas à reflexão leniniana, mas também em razão de suas tensões internas.

Essa tensão foi suficientemente discutida em artigo anterior (Silva, 2017). Para resumir, pode-se dizer que o que limita a construção leniniana de um "projeto de autonomia social" é atribuir, à figuração específica de uma instituição social, o caráter inalterável de norma natural. O princípio político da inapropriabilidade do vlast por qualquer lógica distinta da autoinstituição da maioria é limitada pela perspectiva de que os dispositivos de "administração social" ou "regulação social" e a tecnologia produtiva do capital monopolista devem ser preservados, desenvolvidos e generalizados (Lenin, 1985a; 1985b; 1986). Essa perspectiva não é introduzida como medida estratégica de natureza contingente ou transitória. Na concepção de Lenin, os desenvolvimentos do capital monopolista no campo da gestão e da técnica constituiriam condições necessárias da produção "socializada" e da gestão coletiva da vida política.

Como argumentei no outro artigo, "o esquema explicativo subjacente é aquele que Pierre Dardot e Christian Laval (2014) apreendem sob a legenda da 'produção his-
3. Para uma análise dessas medidas, em uma perspectiva próxima à de Lenin, consultar Martorano (2002). 
tórica do comum pelo capital'" (Silva, 2017: 101). Segundo essa perspectiva, o "comum" (as formas da cooperação de uma futura sociedade comunista) existiria e desenvolver-se-ia em razão da própria lógica interna do desenvolvimento capitalista das forças produtivas, embora as condições para a realização plena e completa de sua potencialidade ou finalidade social ("comum") estejam bloqueadas pelo regime de propriedade e pelas instituições políticas do capitalismo. Decorre dessa perspectiva a concepção da revolução social como a produção consciente da coincidência das formas político-jurídicas com o dinamismo "socializado" das forças produtivas, enfim liberado do bloqueio (externo) das relações de produção do capital.

Para Dardot e Laval (2014), essa concepção exprime uma "deriva teleológica" que, sob o pressuposto da neutralidade dos dispositivos cooperativos, acaba por desativar a "práxis instituinte", em benefício da lógica das formas (instituídas) de subsunção do trabalho ao capital (Silva, 2017: 101).

Limitada por esse "esquema explicativo", a concepção leniniana do vlast sovietal ou comunal inscrevia-se no campo de uma profunda ambivalência. Em considerando, com Deleuze (1997: 23), que "a soberania não reina a não ser sobre aquilo que é capaz de interiorizar", a naturalização leniniana da tecnologia produtiva e do dispositivo de "administração social" do capital monopolista imobiliza a soberania (vlast) da maioria diante de um "fora" que a recaptura como sua suspensão. A incapacidade de conceber esse "fora" como instituição social do capital, e, nesse sentido, de conceber a necessidade de suspender sua vigência na revolução social é o grande

4. Essa leitura evidencia a dificuldade de análises como a de Badiou (2012), que compreende "a submissão da política ao seu desvio estatal" simplesmente como decorrência de um "modelo de emancipação" centrado no partido. Segundo o argumento desenvolvido aqui, esse "modelo", pelo menos em relação a Lenin, não pode ser adequadamente compreendido sem levar em conta aquela "matriz global subjacente". limite da crítica leniniana da estatalidade.

Tal leitura permite compreender que a introdução do partido - ausente nas páginas de Estado e revolução - no esquema estratégico leniniano de 1917 não é expressão da "obsessão pelo poder" frequentemente imputada a Lenin. E não é necessário, como supõe Žižek (2003), recorrer a nenhum silogismo dialético para entender o lugar do partido nesse esquema. Basta reconhecer a presença de algo que Žižek (2003: 171) se recusa a encontrar em Lenin, as "coordenadas dadas por uma matriz global subjacente", aquela da "produção histórica do comum pelo capital". Em Lenin, o papel do partido deriva da concepção de que este representa a consciência científica dessas "coordenadas". À exterioridade dessas "coordenadas" em relação à atividade instituinte das massas corresponde o lugar do partido como representante da exterioridade da consciência científica ${ }^{4}$.

A assunção da necessidade dessa dupla "exterioridade" enreda a crítica leniniana da estatalidade em inescapável tensão. Esta se insinua nos próprios termos - "semiEstado" ou "Estado em definhamento" (Lenin, 1986) - por meio dos quais ele 
pretende sintetizar o caráter da forma política emergente da "destruição" do Estado burguês.

Ao considerar o modo como Lenin explicita o significado desses termos, eles traduzem a concepção de um processo que ainda se move entre Estado e não Estado (Balibar, 1975). Em relação a esse campo de forças em interação dialética, a presença da figura do Estado está relacionada:

i. à necessidade da dominação política enquanto persistirem a resistência das antigas classes dominantes e as diferenças de classe; e

ii. à necessidade de uma "máquina especial de coerção", simplificada e sob forma institucional modificada, para garantir a cooperação dos indivíduos.

O não Estado refere-se:

i. às transformações institucionais da própria "máquina especial" do poder político e à inversão da relação entre maioria e minoria que ela expressa;

ii. ao desenvolvimento de medidas orientadas para a supressão das diferenças de classe; e

iii. ao processo de habituação dos indivíduos à cooperação espontânea (sem coerção).

Há diversos pressupostos problemáticos nessa teoria da "extinção" ou do "definhamento" do Estado, que só podem ser bem compreendidos com a expansão da argumentação de Lenin ${ }^{5}$. No entanto, para a discussão deste artigo, interessa, sobretudo, destacar que, contra o pano de fundo da concepção estratégica global de Lenin, a dinâmica entre "Estado" e "semiEstado" expressa a tensão entre "o 'aparato de Estado', de que necessitamos para realizar o socialismo" (Lenin, 1985b: 317), já preparado pelos dispositivos de "regulação social" produzidos pelo capital, e o "projeto de autonomia social", presente na concepção leniniana de vlast sovietal. Como se sabe, essa tensão foi resolvida, na prática, não no sentido de um movimento em que "é o não Estado que domina o Estado" (Martorano, 2002: 86), mas de um "devir estatal" conectado à instituição de um regime de governamentalidade capitalista específico. Nesse regime, o jogo da representação da soberania na forma Estado-partido e o gigantesco aparato burocrático e repressivo a ela associado constituíam peças fundamentais da tecnologia de controle não somente da produção e da distribuição de recursos, mas de diversas dimensões da vida coletiva e
5. A primeira dificuldade é a redução do problema da supressão das classes à "abolição" da propriedade privada dos meios de produção e à eliminação de diferenças "educacionais", sobretudo conhecimentos e experiência no terreno da técnica e da administração. Outra dificuldade é a condução do problema da cooperação para uma "teoria da habituação" como "teoria da continuidade social da cultura" (Lukács, 2013: 194). Esta ignora a complexidade do problema da forma da cooperação, que coloca a questão da diferença entre a forma capitalista de cooperação e a forma comunal de cooperação. Além disso, presume que a solução do problema se encontra em dois desenvolvimentos: no desenvolvimento das forças produtivas a partir da "base da técnica moderna já lograda" (Lenin, 1986: 98) e supostamente emancipada dos limites do capitalismo pela

"abolição" da propriedade privada dos meios de produção; e no desenvolvimento de algo como uma cultura moral trans-histórica da humanidade - traduzida em "regras elementares de convivência 
conhecidas a largos séculos" (Lenin, 1986: 91) -, a ser emancipada das condições produzidas pela exploração classista e pela limitação da produtividade condicionada por esta. $\mathrm{O}$ problema aqui é a pressuposição de uma racionalidade técnica e de uma racionalidade moral trans-históricas ("neutras") que, emancipadas da sociedade de classes, explicitariam suas normas naturais, quer dizer, sua "essência social verdadeira", como diria Lukács (2013) atado aos mesmos limites que Lenin na problematização do Estado e da transição. Para uma crítica mais detalhada, veja Silva (2017). individual, que se tentava reduzir a uma "função econômica programável" (Dardot \& Laval, 2017: 89) da acumulação de capital. Não se pode evidentemente imputar esse resultado a Lenin, uma vez que se trata do resultado histórico da ação recíproca de uma pluralidade de agências e sujeitos (individuais e coletivos). No entanto, não se pode negar que, movendo-se entre as tensões aqui expostas, ele tenha contribuído para justificar diversas medidas engatadas à produção desse resultado (Bettelheim, 1979; Linhart, 1983; Tragtenberg, 2007; Silva, 2007).

\section{Marx e o sentido da "reabsorção do poder de Estado pela sociedade"}

Guerra civil na França (Marx, 1978) foi redigido em 1871 como Mensagem do Conselho Geral da Associação Internacional dos Trabalhadores. Nesse escrito e em seus dois esboços, enquanto discorre sobre a sucessão de eventos relacionados à emergência e à derrota da Comuna de Paris, Marx analisa o seu significado político, em abordagem que se vale de "amplificação simbólica", no sentido que Santos (2002) atribui a essa operação em uma "sociologia das emergências", ou seja, como recurso para visibilizar e credibilizar alternativas não completamente concretizadas por meio da "amplificação" de suas pistas e sinais e por meio da investigação das condições que podem concretizar sua possibilidade. Ao identificar na Comuna a emergência da forma política de uma revolução contra o Estado, Marx procura tornar visível, em uma leitura a contrapelo do significado "amplificado" das estratégias adotadas pela Comuna, o dinamismo interno da própria forma Estado.

Com o intuito de uma aproximação sem rodeios, pode-se dizer que o conceito de reabsorção é central para a análise de Marx sobre o significado da Comuna de Paris. Esse conceito refere-se à tendência da Comuna de constituir-se como revolução contra a independência ou a separação institucional que caracteriza o Estado como forma essencial de organização da sociedade burguesa.

A Comuna expressaria a tendência de restituir "ao corpo social todas as forças até agora absorvidas pelo parasita estatal", lemos em Guerra civil na França (Marx, 1978: 141). O primeiro esboço desse escrito reconhece na Comuna a forma política de "uma revolução contra o Estado mesmo, esse aborto sobrenatural da sociedade, uma reassunção pelo (by) povo e para (for) o povo de sua própria vida social" (Marx, 1978: 55). É na fórmula desse "by-for" que Marx identifica a negação radical da "usurpação estatal". O Estado é a instituição de uma "força artificial" de controle e subjugação das massas populares, "a força organizada de sua supressão", "sua própria força oposta e organizada contra elas". A Comuna, inversamente, emergiu como a forma política da "reabsorção do poder de Estado pela sociedade como 
suas próprias forças vivas", ou seja, como expressão direta de sua auto-organização (Marx, 1978: 56-57), donde, no texto final, Marx referir-se a ela como "forma de autogoverno dos produtores" (Marx, 1978: 140).

É inegável a similaridade dessa elaboração com certas passagens leninianas em que se insinua um "projeto de autonomia social", no sentido exposto no item anterior. Pode-se dizer que tanto Marx quanto Lenin concebem o enfrentamento da "externalização e duplicação do poder da classe dominante" (Demier \& Gonçalves, 2017: 2361) como problema central para a revolução social. Marx, entretanto, compreende que essa externalização se efetiva não somente por meio da produção de instituições especiais, mas, sobretudo, por meio de sua internalização ou formalização técnica, na instituição de um regime de práticas específico de poder.

Os escritos sobre a Comuna constituem o momento no pensamento de Marx em que se desvenda uma lógica institucional comum a toda uma série de dispositivos ou mediações essenciais do capital. Com efeito, Marx explicita, em relação à rede de dispositivos do Estado, a presença (embora em tecnologias específicas) do mesmo princípio de exteriorização/autonomização do poder e de internalização/ formalização técnica dessa exteriorização que ele havia tematizado na análise do mecanismo da "subsunção real" do trabalho ao capital (Marx, 2004; 2013).

De modo geral, ele aponta duas formas de duplicação entrelaçadas: a duplicação de forças e funções sociais, na forma de forças e funções estatais, pela mediação de "uma divisão sistemática e hierárquica de trabalho" (Marx, 1978: 53); a duplicação de interesses emergentes das "relações dos grupos sociais" (Marx, 1978: 53), na "forma de interesse do Estado", o que permite sua "administração" pela mediação dos produtos da primeira duplicação.

No primeiro esboço de Guerra civil na França, lemos que a maquinaria estatal burguesa substituiu "a anarquia dos poderes medievais conflitantes pelo plano regular de um poder de Estado com uma divisão sistemática e hierárquica do trabalho" (Marx, 1978: 53). No segundo esboço, Marx refere-se ao papel da Revolução Francesa na preparação ou limpeza do solo social para o desenvolvimento da "superestrutura de um poder de Estado centralizado, com órgãos onipresentes ramificados segundo o plano de uma divisão de trabalho sistemática e hierárquica" (Marx, 1978: 103).

Em sua forma abstrata - não em seus dispositivos específicos -, o mecanismo não é muito diferente daquele da "subsunção real do trabalho ao capital". A divisão sistemática e hierárquica do trabalho é o veículo de um processo de expropriação cogni- 
tiva ou técnica dos trabalhadores, o qual confere à figura exteriorizada da unidade de trabalho e da estrutura de comando necessidade técnica. Analogamente ao mecanismo da "subsunção real", as potências intelectuais e habilidosas do processo de trabalho na administração e no governo político passam a existir apenas na forma do "trabalhador coletivo" do Estado, como combinação/unidade exteriorizada dos diversos trabalhos parciais. Esta confronta os trabalhadores do Estado como forma de existência do "poder de Estado unitário", bem como do "poder unitário" ou "plano regular" mais localizado daquela "casta treinada" que, incrustada "nos postos mais altos", controla esta ou aquela ilha de centralização que compõe a maquinaria estatal, "absorvendo as inteligências das massas e voltando-as contra elas mesmas nos postos mais baixos da hierarquia" (Marx, 1978: 56).

Mas essa duplicação não é suficiente para a explicar a forma técnico-política da exteriorização do poder na forma Estado. É preciso considerar ainda, como se pode depreender da análise de Marx, a existência de outra duplicação:

\footnotetext{
Todo interesse solitário menor engendrado pelas relações dos grupos sociais era separado da própria sociedade, fixado e tornado independente dela e oposto a ela na forma de interesse do Estado, administrado pelos padres do Estado com funções hierárquicas determinadas com exatidão (Marx, 1978: 53).
}

À primeira vista, essa análise corresponde ao modelo relacional em que, em geral, as categorias de estrutura e superestrutura são traduzidas. O modelo corrente pressupõe a categoria da anterioridade (a estrutura precede a superestrutura) e um dinamismo hilemórfico (a estrutura põe o "conteúdo" e a superestrutura dispõe-no em uma "forma"). Assim, parece que a estrutura (as "relações dos grupos sociais") põe o "conteúdo" (os interesses), enquanto a superestrutura (no caso, o Estado) dispõe (arruma, ordena e, assim, sanciona) o que está posto em uma "forma" (a "forma de interesse do Estado").

Todavia, ao pensar no conjunto da reflexão proposta nesses escritos de 1871, o modelo não se sustenta, porque o Estado também põe (as "relações dos grupos sociais" do Estado, com seus "padres" e "funções hierárquicas") e, como forma de mediação (das "relações dos grupos sociais"), não se limita a dispor o que está posto, mas efetivamente o transpõe, quer dizer, "fixa", "separa" e "torna independente" em uma forma pela qual ele se torna "administrável" pelas forças sociais duplicadas (transformadas) em forças do Estado, "com funções hierárquicas determinadas com exatidão". É assim que o Estado suprime e bloqueia - "[...] se alimenta da sociedade e bloqueia seu movimento livre [...]" (Marx, 1978: 141) -, acelera e amplia - "O Império [...] contribuiu para acelerar artificialmente a centralização do 
capital [...]" (Marx, 1978: 143) -, incita, suscita, desvia, modula e torna-se capaz de encenar seus próprios acontecimentos.

O Estado não é apenas agente da reprodutividade, mas também da produtividade das relações sociais do capital. Os agenciamentos do Estado operam com e sobre entidades e fluxos (sujeitos, relações, interesses) duplicados e representados ou reapresentados (requalificados e abduzidos) em categorias jurídicas e administrativas, que funcionam como dispositivos de adscrição heterogênea e assimétrica de possibilidades e poder. O Estado é moldado pelas "relações dos grupos sociais", na mesma medida em que molda essas relações, cuja "normalidade" não precede, mas se produz em dinâmica emaranhada com os dispositivos de representação/ duplicação do Estado.

Assim, ao considerar o modo de relação entre o Estado e as "relações dos grupos sociais", a categoria relevante é a da simultaneidade (os termos são simultâneos à relação) - Mészáros refere-se a uma "dialética da simultaneidade" (Mészáros, 2002: 119) - e o dinamismo em jogo não é hilemórfico, mas actancial (os termos são actantes que se modificam em sua mútua mediação). As "relações entre os grupos" põem e o Estado põe e transpõe, mas apenas na medida em que a relação entre os termos cria o âmbito em que a heterogeneidade destes é constituída e mediada. As asserções de Marx (1978: 137) sobre a simultaneidade entre as mudanças do "caráter político" do governo e as "mudanças econômicas da sociedade" podem ser compreendidas como descrevendo um dinamismo de transformações coimplicadas, antes do que a partir da categoria da derivação.

A dupla duplicação conduzida na produção da forma Estado constitui a forma técnico-política de "sua independência da e de seu domínio sobrenatural sobre a sociedade real", afirma o primeiro esboço (Marx, 1978: 53), permitindo-lhe ainda assumir "uma aparência de imparcialidade", enquanto "preserva a atual subordinação das massas", como explica o segundo esboço (Marx, 1978: 103). O Estado absorve e reapresenta actantes sociais e, nessa duplicação, representa sua própria natureza na forma da "imparcialidade" e do "interesse geral".

Todo desenvolvimento do poder de Estado, no sentido de "expandir a circunferência e os atributos do poder estatal, o número de seus instrumentos" (Marx, 1978: 53), adiciona novas camadas de actantes duplicados, novos recursos de "prestidigitação" (sleight of hands) e "malabarismo" (Marx, 1978: 58-59). É assim que o Estado oculta o "diagrama" - "a divisão sistemática e hierárquica do trabalho" - por meio do qual subsume a multiplicidade espaço-temporal de forças e funções sociais acionadas como forças e funções do Estado. É assim que o Estado, dependente 
dos recursos combinados das massas, das inteligências e forças das massas, para a realização de suas funções, produz

a ilusão de que a administração e o governo eram mistérios, funções transcendentes a ser confiadas apenas às mãos de uma casta treinada (Marx, 1978: 56).

Compreende-se, assim, que a "reabsorção do poder de Estado" não poderia, para Marx, restringir-se à destituição dos "padres do Estado" e à abertura de seus "altos postos" aos "agentes comunais" em esquema rotativo e sob (o supostamente possível) controle de seus mandatários. A perspectiva do "by-for" da Comuna demandava uma ruptura radical com a lógica prático-institucional produtora da "transcendência" do poder estatal: a dupla duplicação que constitui sua forma técnico-política ou seu regime de práticas. A forma dessa ruptura não pode ser outra que aquela acionada pela Comuna: a transversalização do tropismo autonômico do "povo atuando para si mesmo e por si mesmo" (Marx, 1978: 39). Essa fórmula simples compreende um dinamismo complexo. O "povo" deve atuar "para si mesmo", ou seja, deve decidir sobre a finalidade de sua atividade comum. Mas isso é possível apenas na medida em que atua "por si mesmo", fora do "diagrama" da "divisão sistemática e hierárquica do trabalho" e das figuras duplicadas do Estado, produzindo a configuração prática e normativa de sua atividade comum, o regime de práticas dentro do qual se faz ativo. Essa forma política não constitui um Estado.

Essa leitura converge com a abordagem de Sayer e Corrigan (1987), Pogrebinschi (2009) e Tible (2014), que argumentam que a Comuna constituía, para Marx, uma forma política adequada à emancipação social "precisamente na medida em que não era um Estado" (Sayer \& Corrigan, 1987: 71). Pogrebinschi, de maneira mais específica, identifica na Comuna algo completamente distinto da forma estatal: forma política constituída pela comunidade, fundada na associação. Essa associação, contrariamente ao que pode supor uma perspectiva pautada no esquema da "produção histórica do comum pelo capital",

não surge como mais um fundamento econômico característico da evolução do capitalismo, mas, ao contrário, estabelece-se em oposição a esse tipo de fundamento (Pogrebinschi, 2009: 134).

Na conceituação da "subsunção real do trabalho ao capital", Marx identifica o "despotismo" (o capital como relação de comando) como componente inerente e indissociável da cooperação produtiva organizada pelo capital, de tal modo que, no desenvolvimento da cooperação capitalista, o "anticomum" do capital constitui-se como forma técnica do processo de trabalho, espécie de "diagrama" que subsume todas as 
formas de interatividade produtiva, convertendo todas as funções e forças produtivas em funções e forças produtivas do capital ${ }^{6}$. Em seus escritos de 1871, ele mostra como funções e forças sociais são duplicadas como funções e forças do Estado, ao serem postas a cooperar "segundo o plano de uma divisão de trabalho sistemática e hierárquica", e como actantes sociais são duplicados em categorias jurídicas e administrativas, assumindo a forma pela qual podem ser "administrados pelos padres do Estado". Assim, em um plano como em outro, o que Marx expõe são as figuras do "anticomum" do capital, que, de nenhum modo, podem oferecer o fundamento para as formas de associação da "emancipação social". A revolução social deve instituir novos regimes de prática como fundamento de suas formas de associação.

Percebe-se, desse modo, a distância abismal do tratamento de Marx da Comuna em relação à perspectiva leniniana de um "mecanismo de administração social" já pronto, produzido pelo próprio dinamismo do capital, e que, livre dos "parasitas", poderia ser ativado pelos "próprios operários unidos" (Lenin, 1986). Enquanto, em Lenin, a naturalização das formas de cooperação do capital no campo econômico permite a proposição da necessidade de conciliar a forma política comunal com outro "aparato de Estado", aquele dos dispositivos de "administração social" ou "regulação social" do capital monopolista, a crítica, em Marx, das formas de cooperação do capital no campo econômico e a crítica do Estado são combinadas em uma crítica radical dos regimes de práticas instituídos na afirmação da dominação do capital.

\section{"Centralismo democrático" versus "constituição comunal"}

As implicações da diferença entre Marx e Lenin acima explicitada talvez fiquem mais claras na discussão da questão da centralização política, explorada nesta seção, e da regulação social da produção, analisada no quarto item.

Percorre a argumentação de Lenin em Estado e revolução a ideia de que a revolução social deve expandir o raio de ação do poder político central e, correlativamente, aumentar o grau de centralização como condição para o controle social das massas populares sobre o conjunto do aparelho. Conectado a essa perspectiva, ele extrai do texto final de Guerra civil na França um modelo de "centralismo democrático". "Marx é centralista", escreve Lenin (1986: 55), "e nos raciocínios que citamos dele não existe o menor desvio do centralismo".

O pressuposto da introdução da fórmula do "centralismo democrático" no contexto da discussão da destruição do Estado burguês é que a ampliação das funções

6. $\operatorname{Marx}(2004 ; 2013)$ analisa a dinâmica da "subsunção real" como um processo de autonomização das potências intelectuais do trabalho e de sua transformação em potências do capital. O princípio básico subjacente a esse processo pode ser compreendido como uma forma de combinação entre:

i. um processo de redução/dissolução do processo de trabalho em seus momentos constitutivos padronizáveis (abstração da atividade);

ii. um processo de transferência de operações abstraídas em um organismo objetivado, organicidade pela qual o conjunto do processo é objetivado e regrado (objetivação estruturante da abstração);

iii. um processo de integração dos produtores imediatos como "apêndices" (efetivadores de uma abstração da atividade) na suplementação ou alimentação do mecanismo objetivado e como "membros conscientes"

(subordinados à organicidade estruturada) na supervisão e correção do processo de trabalho em movimento ou como subjetividade proponente (criadora): iv. uma forma de relação complexa 
entre organicidade objetivada (do mecanismo automatizado) e organicidade subjetiva (forma de interatividade imposta pela superintendência capitalista).

Os agenciamentos concretos pelo qual o processo de "subsunção real" se efetiva atuam tanto nos momentos de dissolução e produção/ configuração interna de funções/ operações quanto nas integrações dessas operações qualificadas. de "administração social" atribuídas aos meios centralizados de governo é inteiramente compatível com ou é mesmo condição para a ampliação do controle social das massas populares. É a coordenação centralizada da atividade de "todos os cidadãos", convertidos em "empregados e operários de um único 'consórcio' do Estado, de todo povo" (Lenin, 1986: 103), segundo o modelo administrativo da "mais alta perfeição técnica" produzido pelo capital monopolista, que, associada àqueles princípios da Comuna de Paris, possibilitaria o "registro e controle" (dístico que aparece em diversos escritos leninianos) da maioria do povo sobre a produção social e a vida social.

A referência ao modelo da empresa ou do consórcio aproxima a reflexão de Lenin da sociologia política weberiana. "O Estado moderno é uma 'empresa' com o mesmo título que uma fábrica: nisto consiste sua especificidade histórica” (Weber, 1998: 1061). Segundo Weber, a mesma separação entre trabalhador e meios de produção que se observa na ordem econômica racional do capitalismo preside a organização burocrática (moderna) do Estado. Os meios materiais administrativos não pertencem ao funcionário profissionalizado, que só pode decidir sobre a "matéria" que lhe cai nas mãos conforme as regras que definem a função do cargo. Isso possibilita que o aparelho burocrático seja organizado de tal forma que a expressão da particularidade ou dos "postulados materiais" ou "valorativos" esteja aprioristicamente excluída e o aparelho exerça eficientemente sua função calculadora não somente sobre a matéria externa (os objetos do Estado), mas também sobre sua própria matéria (seus agentes administrativos).

É essa calculabilidade que, na perspectiva leniniana, torna o "mecanismo de administração social" já pronto do capital monopolista ferramenta útil ao propósito de restituição do poder de Estado à maioria do povo. O distanciamento de Lenin em relação a Weber reside no fato de que, para ele, essa calculabilidade (supostamente neutra) deve ser posta a serviço do controle social dos dispositivos políticos pelas massas populares, ao passo que, para Weber (1993: 128), ela deve ser afastada das massas, na medida em que "a massa desorganizada, a democracia das ruas, é completamente irracional do ponto de vista político". Assim, enquanto Weber propõe dispositivos de bloqueio à influência irracional da "democracia das ruas" sobre o Estado, como o modelo competitivo de relacionamento entre Executivo e Parlamento, Lenin imagina a possibilidade de subordinar essa calculabilidade à racionalidade alternativa da "democracia das ruas" por meio dos dispositivos da Comuna.

No entanto, o que Lenin não apreende e Weber tematiza explicitamente (para naturalizar como necessidade das instituições da modernidade) é que o pressuposto dessa calculabilidade é a neutralização política dos "empregados" dentro desse 
"'consórcio' do Estado", a exteriorização da normatividade que regra e molda o agir comum, a cooperação, em relação a seus agentes imediatos. A fórmula leniniana do "registro e controle" da maioria do povo sugere justamente um controle externo, sobre o aparelho, como contrapartida da destituição política interna de "todos os cidadãos", convertidos em "empregados e operários de um único 'consórcio' do Estado, de todo o povo". O que, no primeiro item deste artigo, foi analisado como uma tensão no pensamento leniniano, parece ser conduzido, em diversas elaborações de Lenin, para uma efetiva dualidade, repondo a "externalização e duplicação do poder" a que se contrapunha a ideia do vlast comunal ou sovietal.

Não por acaso, Lenin argumenta que a participação da maioria na administração política depende do desenvolvimento e incorporação da "cultura capitalista" pelas massas. Segundo ele, o desenvolvimento do capitalismo engendra as premissas da participação da maioria na administração da vida política de três maneiras:

i. pela simplificação da "maioria das funções do velho 'poder de Estado'" no contexto da "cultura capitalista" criada pela grande produção (Lenin, 1986: 50);

ii. pela generalização da alfabetização, necessária à realização dessas funções simplificadas; e

iii. pelo efeito disciplinar (outro componente da "cultura capitalista") do "complexo e socializado aparelho dos correios, das ferrovias, das grandes fábricas, do grande comércio, dos bancos etc." sobre "miIhões de operários" (Lenin, 1986: 103).

O que Lenin identifica como positividade auspiciosa da "cultura capitalista" na fase do capital monopolista é a correspondência entre o nível de simplificação operacional decorrente da divisão funcional sistemática do trabalho e a subjetivação disciplinar dos produtores em escala de massa, ou seja, dois processos engatados aos dispositivos da expropriação cognitiva dos produtores e da articulação hierarquizada das jornadas de trabalho. Lenin não apreende, na simplificação de funções conduzida pela "cultura capitalista", a contrapartida do incremento da complexidade artificial da maquinaria estatal e da divisão hierárquica do trabalho e, por isso, não apreende, na permanência dessa "cultura" e da estrutura de administração correspondente, a reiteração da impossibilidade de qualquer controle social das massas populares. O pressuposto do "registro e controle", como sustentado por Lenin, é a destituição política das massas populares na forma de subjetivação-sujeição, definida segundo as normas (disciplinadoras) da "cultura capitalista" e de seus regimes técnicos de administração. 
Em escritos posteriores a 1917, Lenin identificará a falha desse "registro e controle" da maioria como resultado do "baixo nível cultural" das massas, da lentidão do processo de implantação das estruturas e técnicas do capital monopolista - e, portanto, de gestação da "cultura" (subjetivação) correspondente -, da necessidade (não satisfeita) de difusão, entre as massas populares, da técnica de administração das classes dominantes depostas (Silva, 2007). O problema, contudo, residia em outro lugar: no bloqueio da "autonomia instituinte" das massas (Castoriadis, 1992), do processo de autogoverno inteiramente fundado nos "recursos combinados" das massas populares associadas (Mészáros, 2004), no bloqueio da coprodução autônoma das condições normativas e práticas da própria combinação de seus recursos, bloqueio alimentado pela própria estratégia leniniana de uma "democratização" conduzida por dentro da complexidade artificial da estrutura dos monopólios capitalistas de Estado.

A noção de centralização como condição de calculabilidade generalizada posta a serviço do "registro e controle" da maioria do povo é que induz Lenin àquela interpretação: "Marx é centralista". Trata-se, contudo, de interpretação difícil de sustentar, na medida em que a crítica marxiana da "sobrenaturalidade" dos dispositivos do Estado é incompatível com a manutenção do fetichismo (capitalista) da calculabilidade, que está na base do apego de Lenin ao centralismo. Além disso, Marx critica justamente a abordagem fundada na alternativa centralização/descentralização - que pertence ao léxico do Estado e da crítica burguesa às instituições medievais - na análise do Estado burguês e da novidade da Comuna.

A organização do "poder de Estado unitário" ou a centralização da maquinaria estatal é fundamental para a caracterização da lógica prático-institucional do Estado burguês. No entanto, o Estado burguês emerge, segundo Marx, como dispositivo estratégico e deve, portanto, refletir a lógica sócio-historica específica do afrontamento estratégico em diferentes contextos. Compreende-se, assim, que ele possa desenvolver-se, como na Inglaterra, na forma de um complexo institucional baseado na complementaridade e na competição entre "os grandes órgãos centrais do Estado" e "sacristias corruptas, conselheiros venais e guardiões ferozes das leis-dos-pobres nas cidades e magistrados virtualmente hereditários nos campos" (Marx, 1978: 83). A descentralização, por sua vez, não é suficiente para caracterizar a novidade da Comuna como "antítese" do Estado. A descentralização é uma fórmula capaz de abrigar diversos conteúdos sociais e políticos, até mesmo o "autogoverno" compreendido como "autoadministração das cidades por cavalheiros devoradores de sopa de tartaruga [...] e guardiões ferozes das workhouses" (Marx, 1978: 39). No contexto da Comuna, era o antídoto dos "rurais" contra uma epidemia revolucionária espalhada a partir da capital. 
A Comuna representava virtualmente uma solução diversa do problema, permitindo colocá-lo em outros termos. No primeiro esboço, Marx escreve que a Comuna antecipava a perspectiva de "toda a França organizada em comunas de autotrabalho e autogoverno" (Marx, 1978: 58). Isso não significa, porém, a rejeição de qualquer forma de unidade nacional. Unidade e centralização não são sinônimos. A unidade a ser instituída não poderia reduzir a autonomia do "autogoverno dos produtores" nas províncias, mas deveria constituir-se, ao contrário, como "a expressão deliberada das comunas organizadas", de modo que qualquer princípio de limitação apenas emerge como resultado (revisável) de uma coinstituição horizontal e da coobrigação que ela implica, sendo assumido como princípio de autolimitação.

Enquanto, entre as diversas comunas, poderiam ser estabelecidas formas variadas de conexão direta, não mediada por qualquer organismo político central, o que Marx esperava é que, à "delegação central das comunas federadas", prevista nas proclamações da Comuna, se reservassem "umas poucas funções para propósitos nacionais gerais" (Marx, 1978: 58). No texto final, Marx descreve a reconstituição da unidade nacional como uma lógica de coordenação territorial crescente a partir de um princípio federativo fundado na "constituição comunal", com a delegação distrital das comunas e a delegação nacional das assembleias distritais compostas por representantes estritamente submetidos ao "mandat impératif (instruções formais) de seus eleitores". E remata com a asserção de que

as poucas, mas importantes funções que permaneceriam para um governo central não seriam suprimidas [...] mas seriam desempenhadas por agentes comunais e, portanto, estritamente responsáveis (Marx, 1978: 140).

Tal perspectiva é incompatível com a noção de "uma centralização de outro tipo", que Balibar (1975: 152-153) atribui não somente a Lenin, mas a Marx, permanecendo no horizonte da interpretação leniniana ${ }^{7}$. Como escrevem Sayer e Corrigan (1987: 77), "Marx é claro ao afirmar que a Comuna estabelecia, de uma vez por todas, a redução em escala, poder e custo de qualquer autoridade central", ao mesmo tempo em que aprova "uma forma de sociedade altamente descentralizada". Mas talvez seja mais correto acompanhar Pogrebinschi (2009), que considera que se trata de indagar, primeiramente, se se pode ainda falar em "centro" e qual seria o seu significado.

Nos apontamentos marginais ao Estatismo e anarquia, de Bakunin, Marx escreve que "o sistema começa com o autogoverno das comunidades" (Marx, 1989: 519). Isso quer dizer que o "autogoverno das comunidades" não é um dispositivo com-

7. Essa noção talvez corresponda à abordagem de O 18 Brumário de Louis Bonaparte, de 1852 , em que, ao aludir à futura revolução proletária, Marx assegura que "o esfacelamento da máquina estatal não porá em perigo a centralização", mas apenas a sua "forma vil e brutal", a burocracia (Marx 2011a: 149). Mas é importante registrar que esse trecho foi suprimido na edição de 1869 Essa supressão expressa, segundo Monal (2002), uma mudança na posição de Marx em relação à anterior "valoração positiva da tendência centralizadora do Estado". Minha hipótese é que tal mudança se deve à conceituação da "subsunção real" na década de 1860. 
plementar aos dispositivos de centralização governamental - e menos ainda alguma retórica fachada para coletividades organizadas como "correias de transmissão" de instituições centralizadoras de um Estado-Partido, como sugerem alguns escritos leninianos de 1920-1921, em relação ao papel dos sindicatos e outras instituições proletárias no sistema político pós-revolucionário (Silva, 2007). Os meios de coordenação governamental constituem, ao contrário, um dispositivo derivado do "autogoverno das comunidades" e articulado a partir do princípio político da "constituição comunal", ou seja, a partir do princípio do "autotrabalho" (coprodução de atividades) e "autogoverno" (coprodução da configuração prática e das condições normativas das atividades comuns) por seus membros, no caso, as próprias comunas livremente associadas.

Centralização e descentralização, como antecipado acima, são termos pertencentes ao léxico do Estado. Perdem o sentido em relação a uma forma política não estatal, em que o "centro" não possui, por si mesmo, autoridade, mas é o efeito da coordenação de atividades e decisões de múltiplas "periferias" autogovernadas.

\section{"Produção centralizada" versus "produção social"}

Na segunda seção deste artigo, foi dito que a distinção decisiva entre Marx e Lenin repousa no modo como se articulam a crítica marxiana das formas de cooperação do capital no campo econômico e a crítica marxiana do Estado a partir da plataforma conceitual da "subsunção real". Na presente seção, essa diferença é explorada a partir das suas consequências para a determinação da relação entre a crítica do Estado e o problema da "regulação social" da produção.

Com a fórmula do "centralismo democrático", Lenin pensa ter encontrado o princípio organizativo transversal dos complexos institucionais do poder político e das redes de interconexões das atividades produtivas e distributivas. Sua atratividade deriva de sua correspondência com a perspectiva (obsedante no campo do marxismo de ontem e de hoje) de que a centralização e a concentração de capital engendram os dispositivos do controle coletivo das forças produtivas, o que autoriza deduzir, da própria lógica do desenvolvimento histórico do capitalismo, a viabilidade e mesmo a necessidade da transição ao comunismo.

No quadro dessa concepção, o adjetivo - "democrático" - é facilmente abduzido pelo substantivo. Em diversos momentos depois da Revolução de Outubro, o que parece importar para Lenin é a constituição de 
uma organização estatal harmoniosa que submeta dezenas de miIhões de pessoas à mais rigorosa observação de uma norma única na produção e na distribuição dos produtos (Lenin, 1986b: 309),

bem como "a subordinação incondicional a uma vontade única" (1986c: 205), à autoridade de uma direção unipessoal no local de trabalho. "Produção social" torna-se, assim, sinônimo de "produção centralizada", pressupondo a subordinação das práticas produtivas e distributivas e de seus sujeitos a uma "norma única", a um plano único, e à autoridade da organização social correspondente - que, segundo Lenin (1986d: 143), se pode "aprender dos dirigentes dos trustes", dos "melhores organizadores do capitalismo" -, com suas "personificações" no âmbito dos organismos de gestão econômica do Estado e no âmbito das unidades produtivas.

Nos escritos marxianos sobre a Comuna de Paris, as coisas não são tão claras. Há apenas uma referência en passant a uma regulação da produção nacional "a partir de um plano comum" produzido pelas "sociedades cooperativas unidas" (Marx, 1978: 142), sem nenhum tratamento mais elaborado da relação entre "a redução em escala, poder e custo de qualquer autoridade central" e esse mecanismo de regulação da produção nacional.

Apesar da vagueza da formulação, há aqui a sugestão de que a regulação da produção nacional deve ser construída ao lado do (e não pelo) sistema político fundado na "constituição comunal". A questão que emerge é se a "constituição comunal" pode ser compreendida igualmente como princípio político da "produção social". No caso de resposta afirmativa - na verdade, já antecipada na segunda seção do artigo -, a pergunta desdobra-se na indagação sobre o significado desse "plano comum" e a natureza das "sociedades cooperativas", bem como da unidade entre elas.

É significativo que, no primeiro esboço, precisamente ao falar do "trabalho organizado em larga escala" como "base material" do movimento do proletariado, Marx sublinhe a oposição entre "trabalho despoticamente organizado" e "trabalho associado livre", entre "meios de produção centralizados" e "meios de produção sociais", apontando para a necessidade de o proletariado "transformar o caráter capitalista atual daquele trabalho organizado e daqueles meios de trabalho" (Marx, 1978: 61). Em um texto em que "a ausência de vida em toda parte" é identificada como resultado da centralização estatal (Idem: 75), acredito que a oposição entre os termos "centralizado" e "social" dessa passagem deva ser levada a sério e interpretada efetivamente como indicação de uma distinção qualitativa entre "produção centralizada" e "produção social". 
Nos Grundrisse, Marx (2011) localiza a diferença entre o "caráter social" ou "coletivo" de uma produção efetivamente social ou coletiva e da produção capitalista nas formas de mediação. Resumidamente, o que caracteriza a produção capitalista, em relação a essa dimensão, é a indiferença mútua entre as unidades produtivas e a conexão externa e post festum entre elas, dado que seu "caráter coletivo" é posto pela troca de mercadorias, sendo regulado por uma normatividade que aparece como "relação natural externa aos indivíduos", pela "divisão do trabalho gerada na troca de valores" e suas respectivas "leis econômicas" (Marx, 2011: 119). A mediação tem, assim, uma forma objetivada ou reificada, interligando "produções mutuamente indiferentes" e subordinando os indivíduos a normas e condições produzidas à sua revelia, pelas relações recíprocas (não deliberadas) entre essas produções. Na produção efetivamente social ou coletiva, "o próprio pressuposto é mediado", ou seja, o "caráter social" da produção é resultado de uma instituição coletiva, que regula diretamente a troca de atividades produtivas de acordo com necessidades e finalidades coletivamente deliberadas. É "a associação que reparte o trabalho entre seus membros", bem como estabelece a "distribuição planificada do tempo de trabalho entre os distintos ramos de produção" (Marx, 2011: 118119). A mediação ocorre, assim, na troca de atividades, não por meio da troca de produtos, ou seja, ante festum, e por meio da coinstituição.

Não se pretende sugerir a possibilidade de alinhar a perspectiva dos escritos marxianos de 1871 sobre a Comuna de Paris e a dos Grundrisse no que se refere à questão em pauta. Em primeiro lugar, porque, no tempo que os separa, emerge a plataforma conceitual da "subsunção real" como novo ponto de partida para a crítica da centralização. Em segundo lugar, porque, nos escritos sobre a Comuna, a questão não é suficientemente desenvolvida, limitando-se ao equacionamento de "despotismo" capitalista e centralização, contraposto à perspectiva da "associação livre" como fundamento da produção social. No entanto, a elaboração dos Grundrisse pode ser aproveitada para fazer avançar a discussão.

Nos Grundrisse, o que é fundamental na caracterização da "produção social" não é qualquer planejamento centralizado, mas a mediação do "próprio pressuposto", a coinstituição do "social", do modo e das regras que estruturam a conexão entre as atividades produtivas, pelos sujeitos coparticipantes dessas atividades. Ainda, para mais das considerações de Marx, pode-se afirmar que planejamento e centralização não são incompatíveis com a indiferença mútua entre as unidades produtivas e sua conexão meramente externa. Como observa Turchetto (2005: 28), em passagem elucidativa, a ligação entre as unidades produtivas "permanece exterior seja quando é confiada ao 'jogo espontâneo' do mercado, seja quando vem imposta autoritariamente ex ante mediante a planificação". Mészáros (2002: 884) analisa o "planeja- 
mento" no que ele chama "economia dirigida" como não mais que a extensão de um controle autoritário sobre a troca de produtos, "um 'planejamento' post festum bastante defeituoso", que tem como resultado privar "o sistema reprodutivo até mesmo do limitado mecanismo de feedback" do mercado, que permite realizar "ajustes viáveis na operação dos empreendimentos produtivos afetados" (Mészáros, 2002: 885).

Apesar da vagueza das formulações marxianas sobre o modo de regulação da produção social nesses escritos de 1871, elas permitem conceber, como proposição política associada àquelas estabelecidas no texto, a extensão do princípio político da "constituição comunal" para o sistema de regulação da produção social pelas "sociedades cooperativas unidas", constituído ao lado da e em conexão com a coordenação federativa das comunas. A base desse sistema seria o autogoverno das sociedades cooperativas de produção e de consumo e a coinstituição do modo, das regras e dos fins coletivos que estruturam suas conexões em diferentes escalas e formas interescalares. Essas conexões poderiam, quando necessário, mobilizar formas de delegação federada, mas estariam subordinadas menos a uma lógica territorial do que às necessidades de regulação dos fluxos materiais em razão dos quais elas se constituiriam (incluindo aqueles necessários à reciclagem orgânica dos excrementos da produção e do consumo, que passa a preocupar Marx a partir da década de 1860). O "plano comum", nesse sentido, seria a transcrição dessa malha complexa de interações e processos de codecisão multilaterais e, além dela, a coprodução de regras e soluções para facear possíveis iniquidades e necessidades que envolvam fluxos materiais em escala mais abrangente.

Pode-se dizer que essa perspectiva se assemelharia àquela que Dardot e Laval propõem como uma "lógica institucional de dupla horizontalidade":

[...] de um lado, a federação dos comuns constituídos sobre base socioeconômica; de outro, a federação dos comuns estabelecidos sobre base puramente territorial [...]. Entre esses dois tipos de comuns estabelece-se uma relação horizontal cruzada, de tal modo que: 1) os comuns socioeconômicos (comuns de produção, de consumo, bancos de sementes etc.) são constituídos independentemente de qualquer lógica territorial, isto é, apenas em função do encargo das coisas pelos quais eles se formaram [...]; 2) em contrapartida, os comuns políticos se constituem segundo uma lógica de integração crescente entre os territórios; eles fazem prevalecer em determinado território regras que garantem a coordenação dos comuns sociais de seu âmbito (Dardot \& Laval, 2017: 519).

Marx em nenhum lugar desenvolveu o significado e as condições de possibilidade do regime de práticas da "produção social" com o mesmo grau de clareza com que 
o fez em relação ao regime de práticas da forma política da "emancipação social" nas páginas sobre a Comuna. Podemos apenas extrair as implicações de sua crítica da "subsunção real do trabalho ao capital" e de algumas poucas pistas, como aquelas exploradas nesta seção. Não obstante, o que parece claro, pelas ressonâncias entre a crítica marxiana das formas de cooperação do capital no campo econômico na década de 1860 e a crítica marxiana do Estado em 1871, é que a investigação de formas apropriadas para a "emancipação social" passa por uma crítica radical dos regimes de práticas instituídos na afirmação da dominação do capital na economia e na política.

\section{Considerações finais}

A abordagem de Marx permite reconhecer a "produção histórica" do "anticomum" do capital na economia e na política, pelo desvendamento de um regime de práticas transversal, fundado na divisão sistemática e hierárquica do trabalho e nas diversas formas de "duplicação" encarnadas nas tecnologias que ela (a divisão do trabalho) permite produzir nas duas "esferas". A oposição entre cooperação "despoticamente organizada" e cooperação "associada" e entre meios "centralizados" e meios "sociais" constitui um pano de fundo conceitual essencial para a alternativa que emerge das páginas de Marx sobre a Comuna, em que se anuncia não a identidade entre as instituições do "comum" na economia e na política, mas o princípio político de um regime de práticas comum a ambas, a partir das categorias da "reabsorção", da "associação", do "autotrabalho" e do "autogoverno".

Já, em Lenin, o esforço de conceber um regime de práticas alternativo no campo político esbarra na naturalização das formas de cooperação do capital no processo de trabalho ("a base da técnica moderna") e na esfera da circulação (os dispositivos de "administração" e "regulação social" do capital monopolista valorizados por Lenin). É essa naturalização que está na base do jogo que Lenin estabelece entre Estado e não Estado e entre centralização e democracia na reflexão sobre a Comuna, ambivalência que revela o limite da crítica leniniana da estatalidade e de seu "projeto de autonomia social".

Esse limite reaparece, sob diferentes formas, na atualidade, não apenas no campo das esquerdas que, orbitando ainda a fórmula da "estatização dos meios de produção", interpretam as lutas em defesa das propriedades estatais ou por sua ampliação como avanços na direção do socialismo, na contramão da crítica marxiana à expansão da "circunferência" e dos "atributos do poder estatal". Ressurge também em muitas das críticas ao estatismo dominante e à "fidelidade ao consenso democrático" (Žižek, 2002: 167), no campo da imaginação política anticapitalista. 
É o caso da perspectiva da "determinação ontonegativa da politicidade" de Chasin (2000: 63, 67, 69), que, pela incapacidade de exercitar uma crítica do regime de práticas de poder que dá forma às forças produtivas do capital, localiza a "determinação positiva" da revolução social na necessidade da "reapropriação das potências produtivas sociais", segundo o grau de universalidade e racionalidade alcançado na última forma do desenvolvimento do sistema capitalista. A crítica da "perfectibilização da política" e do Estado, como expressão de uma esquerda que cedeu ao fascínio dos dispositivos de representação e dos procedimentos democráticos, termina, assim, na afirmação da necessidade da "perfectibilização" das "potências produtivas sociais" do capital.

É o caso também de Žižek, que se sente tentado "a parafrasear o bem conhecido slogan de Lenin 'Socialismo = eletrificação + poder dos sovietes'” (Žižek, 2002: 294). Para Žižek, esse "datado" slogan leniniano, como outros em torno dos aparatos de administração social do capital monopolista, podem ser atualizados ("repetidos") em "uma teoria da World Wide Web" (Žižek, 2002: 293). O tema central para essa teoria, do ponto de vista da emancipação, seria o acesso aos meios de controle social da World Wide Web, o que, além da problemática da propriedade, coloca o problema da forma política, donde o slogan atualizado: "'Socialismo = livre acesso à Internet + poder dos sovietes'" (Žižek, 2002: 294). Nessa teoria de um "Lenin ciberespacial” ou da "economia pós-industrial", o que "se repete" é "o esquema da produção histórica do comum pelo capital". Com efeito, não se trata da instituição do "comum", mas da emancipação de um suposto "comum" produzido pelo capital nas formas de comunicação e cooperação reticulares da "economia pós-industrial".

Essa abordagem não é exclusiva de Žižek. Muitos dos teóricos do assim chamado "capitalismo cognitivo" - como Hardt e Negri (2005) - sustentam que a produção do "comum" dentro do capitalismo entrou em nova fase de "espiral dinâmica e expansiva", limitada apenas pelos dispositivos da extração rentista e do biopoder instalado no tecido social ${ }^{8}$. E, ainda que distante desse referencial e concentrado na simplificação das atividades administrativas estatais, é possível ler em um marxista de linhagem mais "clássica" - como Martorano (2002: 85) - que "quando a Internet e o uso de computadores se tornam uma simples brincadeira de crianças, pode-se concluir que o Estado socialista é tecnologicamente possível". O que vale dizer aqui, a partir do argumento desenvolvido no artigo, diz respeito à necessidade de romper com a noção de qualquer pressuposto técnico para a destruição do Estado e a emancipação social e, sobretudo, com a assunção das formas tecnológicas do "incomum" do capital como sua precondição. Se há um pressuposto técnico, esse não é outro que o ataque aos pressupostos técnicos do capital e do Estado, o revolucionamento do regime de práticas do poder no campo econômico e no campo político.

8. Veja a impecável crítica de Dardot \& Laval (2017) a Hardt, Negri e Vercellone. 
Para encerrar, é importante recordar que o substantivo "Estado" tem peso muito importante no léxico do imaginário crítico anticapitalista. E sua importância tem aumentado no contexto defensivo da resistência à "pilhagem" do público-estatal orquestrada pelas oligarquias com apoio dos governos. Com efeito, a defesa dos serviços públicos, embora razoável do ponto de vista de seu significado para a satisfação de certo conjunto de necessidades de amplos setores sociais, tem como efeito colateral amplificar a vocalização da concepção do Estado como institucionalidade alternativa ao mercado. Neste contexto, a démarche marxiana convida-nos a ir além da fascinação pela oscilação pendular entre privado e público-estatal. Incita-nos a analisar os regimes de práticas que estruturam as formas privada e pública de produção ou regulação de "bens" e "serviços" e a produzir, em experimentações coletivas diversas e em sua "ecologização", em oposição às lógicas conjugadas do público-estatal e do privado, tecnologias de "autotrabalho" e "autogoverno" na multiplicação de formas associativas orientadas para a "reabsorção" dos poderes subsumidos pelos dispositivos econômicos e políticos do capital.

\section{Referências}

ALTHUSSER, Louis. Posições-2. Rio de Janeiro: Graal, 1980.

ANWEILER, Oscar. The soviets: the Russian workers, peasants, and soldiers councils, 1905-1921. New York: Pantheon Books, 1974.

BADIOU, Alan. A hipótese comunista. São Paulo: Boitempo, 2012.

BALIBAR, Étienne. Cinco estudos sobre o materialismo histórico, v. 1. Lisboa: Presença; Martins Fontes, 1975.

BETTELHEIM, Charles. A luta de classes na União Soviética: primeiro período (19171923). Rio de Janeiro: Paz e Terra, 1979.

BOBBIO, Noberto. A teoria das formas de governo na história do pensamento político. Brasília: Universidade de Brasília, 1980.

CASTORIADIS, Cornelius. As encruzilhadas do labirinto VI: figuras do pensável. Rio de Janeiro: Civilização Brasileira, 2004.

- Encruzilhadas do labirinto III: o mundo fragmentando. Rio de Janeiro: Paz e Terra, 1992.

CHASIN, José. Ensaios Ad Hominem 1, v. 3: a determinação ontonegativa da politicidade. Santo André (SP): Ad Hominem, 2000. 
DARDOT, Pierre; LAVAL, Christian. Comum: ensaio sobre a revolução no século XXI. São Paulo: Boitempo, 2017.

Commun: essai sur la révolution au XXIe siècle. Paris: La Découverte, 2014.

DELEUZE, Gilles. Mil Platôs: capitalismo e esquizofrenia, v. 5. São Paulo: Editora 34, 1997.

DEMIER, Felipe; GONÇALVES, Guilherme Leite. Capitalismo, Estado e democracia: um debate marxista. Direito e Práxis, v. 8, n. 3, 2017.

FERNANDES, Florestan. Apresentação. In: LENIN, V. I. O Estado e a revolução. São Paulo: Expressão Popular, 2010.

HARDT, Michael; NEGRI, Antonio. Multidão: guerra e democracia na Era do Império. Rio de Janeiro: Record, 2005.

LENIN, Vladimir I. El Estado y la revolución. In: LENIN, V. Obras completas, v. 33. Moscou: Progreso, 1986 [1917].

El marxismo y el Estado. In: LENIN, V. Obras completas, v. 33. Moscou: Progreso, 1986a [1917].

Acerca del infantilismo "izquierdista" y del espíritu pequeñoburgués. In: LENIN, V. I. Obras completas, v. 36. Moscou: Progreso, 1986b [1918].

Las tareas inmediatas del poder soviético. In: LENIN, V. I. Obras completas, v. 36. Moscou: Progreso, 1986c [1918].

_. Primera variante del artículo "Las tareas inmediatas del poder soviético". In: LENIN, V. I. Obras completas, v. 36. Moscou: Progreso, 1986d [1918].

— Las tareas del proletariado en la presente revolución. In: LENIN, V. I. Obras completas, v. 31. Moscou: Progreso, 1985 [1917].

- Materiales para la revisión del programa del partido. In: LENIN, V. I. Obras completas, v. 32. Moscou: Progreso, 1985a [1917].

Se sostendrán los bolcheviques en el poder? In: LENIN, V. I. Obras completas, v. 34. Moscou: Progreso, 1985b [1917].

LIH, Lars T. De Fevereiro a Outubro. Carta maior, 2017. Disponível em: <https:// www.cartamaior.com.br/?/Editoria/Arte/De-Fevereiro-a-Outubro/39/38369>. Acesso em: 22 Jan. 2019. 
LINHART, Robert. Lenin, os camponeses, Taylor. Ensaio sobre a origem do sistema produtivo soviético. Rio de Janeiro: Marco Zero, 1983.

LUKÁCS, György. The culture of people's democracy: Hungarian essays on literature, art, and democratic transition, 1945-1948. Leiden; Boston: Brill, 2013.

MARTORANO, Luciano C. A burocracia e os desafios da transição. São Paulo: Xamã; Anita Garibaldi, 2002.

MARX, Karl. O capital: crítica da economia política - Livro I. São Paulo: Boitempo, 2013 [1867].

_. Grundrisse. São Paulo; Rio de Janeiro: Boitempo; Editora UFRJ, 2011 [18571858].

. O 18 de brumário de Luís Bonaparte. São Paulo: Boitempo, 2011a [1852; 1869].

—. Capítulo sexto inédito de O Capital. São Paulo: Centauro, 2004 [1863-1866].

- Notes on Bakunin's book Statehood and anarchy. In: Marx-Engels collected works, v. 24. Londres: Lawrence and Wishart, 1989 [1875].

- The Civil War in France; The Civil War in France - first draft; The Civil War in France - second draft. In: Marx-Engels Gesamtausgabe, v. I/22. Berlin: Dietz, 1978 [1871].

MÉSZÁROS, István. O poder da ideologia. São Paulo: Boitempo, 2004.

—. Para além do capital. São Paulo: Boitempo, 2002.

MONAL, Isabel. Carlos Marx, la sociedad civil y el socialismo. Lutas sociais, v. 8, 2002.

POGREBINSCHI, Thamy. O enigma do político. Rio de Janeiro: Civilização Brasileira, 2009

POULANTZAS, Nicos. O Estado, o poder, o socialismo. São Paulo: Paz e Terra, 2000.

SANTOS, Boaventura de Sousa. Para uma sociologia das ausências e uma sociologia das emergências. Revista Crítica de Ciências Sociais, v. 63, 2002.

SAYER, Derek, CORRIGAN, Philip. Revolution against the State: the context and significance of Marx's later writings. Dialectical Anthropology. v. 12, n. 1, 1987. 
SILVA, Rafael Afonso da. Entre o "comum" da autoinstituição e o "comum" do capital: 100 anos de Estado e revolução. Lutas Sociais, v. 21, n. 38, 2017.

. Dilemas da transição: um estudo crítico da obra de Lenin de 1917-1923. Dissertação (Mestrado em Sociologia) - Universidade Estadual de Campinas (Unicamp), Campinas (SP), 2007.

SITTON, John F. Marx's theory of the transcendence of the State. New York: Peter Lang, 1989.

TIBLE, Jean. Marx contra o Estado. Revista Brasileira de Ciência Política, v. 13, 2014.

TRAGTEnBERG, Maurício. A Revolução Russa. São Paulo: Editora Unesp, 2007.

TURCHETTO, Maria. As características específicas da transição ao comunismo. In: NAVES, M. B. (Org.). Análise marxista e sociedade de transição. Campinas (SP): Editora Unicamp, 2005.

WEBER, Karl E. M. Economia y sociedad. México: Fondo de Cultura Económica, 1998.

- Parlamento e governo na Alemanha reordenada: crítica política do funcionalismo e da natureza dos partidos. Petrópolis (RJ): Vozes, 1993.

ŽIŽEK, Slavoj. De História e consciência de classe à dialética do esclarecimento, e volta. Lua nova, v. 59, 2003.

. Afterword: Lenin's choice. In: LENIN, Vladimir I. Revolution at the gates: a selection of writings from february to october 1917. Londres; New York: Verso, 2002. 
